\title{
Knowledge and Attitudes of Black South African Women toward Menopause: Impact of Culture and Traditions
}

\author{
${ }^{1}$ Lineo Matsela, ${ }^{2}$ Olakunle Towobola, ${ }^{3}$ Ephraim T Mokgokong
}

\begin{abstract}
Introduction: Vasomotor symptoms of menopause could affect the quality-of-life of most women. The understanding of menopause by African women and the coping mechanisms of these women are essential factors that may be influenced by culture and traditions. This study has evaluated the psychosomatic and sociodemographic profiles of menopausal black South African women in order to ascertain the role played by their culture and traditions during the menopausal years.
\end{abstract}

Materials and methods: The study was carried out at three periurban districts close to the city of Pretoria, South Africa. A qualitative, prospective, community-based, cohort study was conducted over a 2-year period. The targeted population included women between 40 and 80 years, and each woman was interviewed using a structured questionnaire. Data on sociodemographic, psychosomatic profiles of the women as well as cultural and traditional beliefs relating to menopause were documented. The data from the study were analyzed by descriptive statistics.

Results: Totally, 450 women were interviewed: 250 (perimenopausal) and 200 (postmenopausal). The ages of the women ranged between 42.5 and 50.8 years (perimenopausal) and between 51.5 and 68.4 years for postmenopausal women. Only $20 \%$ of the women interviewed for the study had no formal education and $78 \%$ of them were financially independent. The percentage of the women who had an understanding of menopause and expressed cultural explanations for it was $96 \%$. The women explained the impact of support systems on which they relied and by which their attitudes toward menopause were greatly influenced. Knowledge of hormone replacement therapy (HRT) and its importance in the alleviation of vasomotor symptomatology ranged between 80 and $84 \%$, yet the women were reluctant to seek medical remedy for their vasomotor symptoms.

Conclusion: The study provides insight into the impact that traditions and culture of black South African women have on their capacity to cope with menopause.

Keywords: Attitudes and knowledge, Black South African women, Culture and traditions, Menopause.

\footnotetext{
${ }^{1-3}$ Professor

1,3 Department of Obstetrics and Gynecology, Sefako Makgatho Health Sciences University, Pretoria, Gauteng, Republic of South Africa

${ }^{2}$ Department of Internal Medicine and Clinical Research, Sefako Makgatho Health Sciences University, Pretoria, Gauteng Republic of South Africa

Corresponding Author: Lineo Matsela, Professor, Department of Obstetrics and Gynecology, Sefako Makgatho Health Sciences University, Pretoria, Gauteng, Republic of South Africa Phone: +27125214461, e-mail: lineomatsela@yahoo.com
}

How to cite this article: Matsela L, Towobola O, Mokgokong ET. Knowledge and Attitudes of Black South African Women toward Menopause: Impact of Culture and Traditions. J South Asian Feder Menopause Soc 2017;5(2):117-122.

Source of support: Nil

Conflict of interest: None

Date of received: 29 July 2017

Date of acceptance: 17 September 2017

Date of publication: December 2017

\section{INTRODUCTION}

Menopause is defined as the permanent cessation of menstruation due to the loss of follicular activity and an inadequate hormonal support. It is manifested by amenorrhea for 12 conservative months without any physiological or pathological cause. ${ }^{1}$ Menopause is a form of endocrinopathy, the clinical manifestations of which are affliction of the specific pelvic and extrapelvic organs including the brain and skeletal systems. ${ }^{2}$

Menopause in the African women is viewed as a physiological change from reproductive age to cessation of menstruation. It is perceived by many African women as a stage of wisdom and experience, since the postmenopausal woman has the knowledge of the reproductive career and the rearing of children and grandchildren. ${ }^{3-6}$

The postmenopausal woman is given elevation of status as well as a state of liberation from reproduction. ${ }^{3-6}$ Menopause is viewed as a stage of tranquility, freedom from childbirth and its complications. ${ }^{7}$

Early manifestations of the effects of menopause are the vasomotor symptoms that women are subjected to ${ }^{8,9}$ and for which African women are slow to seek medical help. However, vast differences in the understanding and the need to seek expert help exist among different racial groups. ${ }^{10}$ The degree to which African women have embraced knowledge about menopause as well as the impact of culture and tradition on this understanding have been explored among black South African women in this study.

This study, therefore, enabled an establishment of the age at which black South African women attain menopause and the psychosomatic behavior of such women living in three periurban districts (Odi, Soshanguve, and Ga-Rankuwa) of Pretoria, South Africa. 


\section{OBJECTIVES}

Three objectives were the focus of the study:

1. To establish the age at which menopause occurs.

2. To determine the level of understanding of menopause and assess the impact of cultural and traditional norms on the understanding of menopause by these women.

3. To establish the psychosomatic aspects of menopause among black South African menopausal women.

\section{MATERIALS AND METHODS}

The study was carried out in the Ga-Rankuwa, Odi, and Soshanguve districts-these are periurban areas, which fall within the Gauteng Province and the border regions of North West Province of South Africa. A prospective, community-based, descriptive cohort study was conducted. The target population included women aged between 40 and 80 years, who resided in any of the three districts between January 1, 2007 and December 31, 2009. Eligible participants were chosen randomly and interviewed individually in their homes. The interviews were conducted using a structured questionnaire written in English, but translated for the participants into their respective languages/dialects. Those who could understand English were interviewed in English. Questions were drafted as either open-ended or categorical, to elicit information from the women regarding age at menopause, the level of their understanding of menopause, and assess the impact of cultural and traditional norms on that understanding.

The study was approved by the Institutional Ethics Committee of the Sefako Makgatho Health Sciences University and an informed consent was obtained from each of the participants who took part in the study. Data were collected on sociodemographic and psychosomatic variables, and the traditional and cultural beliefs about
Table 1: Classifications of the ethnic groups in the study

\begin{tabular}{lll}
\hline Ethnic groups & Perimenopausal & Postmenopausal \\
\hline Tswana & $69(27.6 \%)$ & $46(23.0 \%)$ \\
Zulu & $61(24.3 \%)$ & $59(29.5 \%)$ \\
Northern Sotho & $54(21.7 \%)$ & $50(25.0 \%)$ \\
Tsonga & $66(26.3 \%)$ & $45(22.5 \%)$ \\
Total & 250 & 200 \\
\hline
\end{tabular}

menopause were fully explored from the women. The women elaborated on their coping mechanisms for the physiological and psychological effects of menopause.

\section{RESULTS}

A total of 450 women were interviewed among the four ethnic groups. All the participants were classified as either being perimenopausal or postmenopausal. The four ethnic groups that were sampled for this study were all residents of the districts and represent the sampling profile of the participants classified as either perimenopause or postmenopause (Table 1).

Other social characteristics among the four ethnic groups are illustrated in Table 2, which provides information on age, marital status, educational levels, and employment status. Perimenopausal women were aged between 42.5 and 50.8 years [mean age, 44.6; standard deviation (SD), 3.6], and postmenopausal women were aged between 51.5 and 68.4 years (mean, 63.4; SD, 7.2). Majority of the women were married (74\%; perimenopausal; $62 \%$ postmenopausal) at the time of their interviews. Only $20 \%$ of all the women interviewed had no formal education and close to $50 \%$ of all the women had 12 or more years of education. Most of the women $(78 \%)$ were still gainfully employed at the time of participating in this study, although the number in employment was predominantly the perimenopausal women.

Table 2: Social characteristics of participants in the study (250 perimenopausal and 200 postmenopausal women)

\begin{tabular}{|c|c|c|c|c|}
\hline \multirow{2}{*}{$\begin{array}{l}\text { Social characteristics } \\
\text { Age (years): }\end{array}$} & \multicolumn{2}{|c|}{ Range } & \multicolumn{2}{|c|}{ Mean $( \pm S D)$} \\
\hline & & & & \\
\hline Perimenopausal & \multicolumn{2}{|c|}{$42.5-50.8$} & \multicolumn{2}{|c|}{$44.6 \pm(3.6)$} \\
\hline Postmenopausal & \multicolumn{2}{|c|}{$51.5-68.4$} & \multicolumn{2}{|c|}{$63.4 \pm(7.2)$} \\
\hline Marital status & Married & Divorced & Widowed & Never married \\
\hline Perimenopausal & $74 \%$ & $21 \%$ & $28 \%$ & $5 \%$ \\
\hline Postmenopausal & $62 \%$ & $36 \%$ & $37 \%$ & $2 \%$ \\
\hline Parity & \multicolumn{2}{|c|}{ Perimenopausal } & \multicolumn{2}{|c|}{ Postmenopausal } \\
\hline 0 & \multicolumn{2}{|c|}{$18(7.2 \%)$} & \multicolumn{2}{|c|}{$12(5.8 \%)$} \\
\hline $1-2$ & \multicolumn{2}{|c|}{$125(50.0 \%)$} & \multicolumn{2}{|c|}{$48(23.9 \%)$} \\
\hline $3-4$ & \multicolumn{2}{|c|}{$71(28.3 \%)$} & \multicolumn{2}{|c|}{$65(32.6 \%)$} \\
\hline$\geq 5$ & \multicolumn{2}{|c|}{$36(14.5 \%)$} & \multicolumn{2}{|c|}{$75(37.7 \%)$} \\
\hline \multicolumn{5}{|l|}{ Education $(n=450)$ : } \\
\hline No education & \multicolumn{2}{|c|}{$20 \%$} & \multicolumn{2}{|c|}{-} \\
\hline$<12$ years of education & \multicolumn{2}{|c|}{$33 \%$} & \multicolumn{2}{|c|}{-} \\
\hline$\geq 12$ years of education & \multicolumn{2}{|c|}{$47 \%$} & \multicolumn{2}{|c|}{-} \\
\hline \multicolumn{5}{|l|}{ Employment $(n=450)$ : } \\
\hline Employed & \multicolumn{2}{|c|}{$78 \%$} & \multicolumn{2}{|c|}{-} \\
\hline Unemployed & \multicolumn{2}{|c|}{$22 \%$} & \multicolumn{2}{|c|}{-} \\
\hline
\end{tabular}


Table 3: Responses to questions relating to the understanding of issues around menopause by the different ethnic groups

\begin{tabular}{|c|c|c|c|c|}
\hline \multirow[b]{2}{*}{ Questions } & \multicolumn{4}{|c|}{ Ethnic groups } \\
\hline & Tswana & Zulu & Northern Sotho & Tsonga \\
\hline Does your & Yes & Yes & Yes & Yes \\
\hline $\begin{array}{l}\text { culture have any } \\
\text { explanation for } \\
\text { menopause? }\end{array}$ & $95 \%$ & $98 \%$ & $94 \%$ & $95 \%$ \\
\hline $\begin{array}{l}\text { What is the role of a } \\
\text { menopausal woman } \\
\text { in your community? }\end{array}$ & * & * & * & * \\
\hline $\begin{array}{l}\text { What are the } \\
\text { traditional taboos } \\
\text { for menopausal } \\
\text { women in your } \\
\text { culture? }\end{array}$ & None & None & None & None \\
\hline
\end{tabular}

*Answers to questions given by all four ethnic groups (Table 3):

1. They sit in community elders' council to discuss community issues.

2. They are regarded as elders who advise the youth. They are seen as being "clean" because they no longer have menstruation and can now participate actively as traditional birth attendants.

3. Being "clean," they are allowed to provide the needs of initiates at traditional circumcision ceremonies.

In Table 4, only a small percentage (between 4 and $10 \%$ ) of the women had negative feelings toward becoming menopausal. Menopause is also not associated with the women losing their minds and the appearance of wrinkles following menopause, although observed by all the women (18-22\%), its occurrence was not considered to be a bothersome change. The presence of beard was also identified by a small group of women (5-8\%) in the study, but, in general, they all reported that its presence had not affected them either personally or socially.

Table 5: Participant's perceptions of the impact of menopause on their fertility

\begin{tabular}{lllll}
\hline & \multicolumn{3}{c}{ Ethnic groups } \\
\cline { 2 - 5 } & \multicolumn{3}{c}{ Northern } \\
Questions & Tswana & Zulu & Sotho & Tsonga \\
\hline $\begin{array}{l}\text { Are you pleased with the } \\
\text { cessation of menstruation? }\end{array}$ & $85 \%$ & $79 \%$ & $88 \%$ & $92 \%$ \\
$\begin{array}{l}\text { Answer: (Yes) } \\
\text { Are you happy that you }\end{array}$ & $95 \%$ & $92 \%$ & $98 \%$ & $94 \%$ \\
$\begin{array}{l}\text { can no longer become } \\
\text { pregnant? Answer: (Yes) }\end{array}$ & & & & \\
$\begin{array}{l}\text { Are you happy that you can } \\
\text { no longer suffer from labor }\end{array}$ & $98 \%$ & $96 \%$ & $97 \%$ & $95 \%$ \\
$\begin{array}{l}\text { pains and complications } \\
\text { of child-bearing? Answer: } \\
\text { (Yes) }\end{array}$ & & & & \\
$\begin{array}{l}\text { Are you worried that your } \\
\text { husband will have no more } \\
\text { children? Answer: (No) }\end{array}$ & $96 \%$ & $98 \%$ & $91 \%$ & $93 \%$ \\
\hline
\end{tabular}

Table 4: Assessment of women's self-awareness after menopause

\begin{tabular}{|c|c|c|c|c|}
\hline \multirow[b]{2}{*}{ Questions } & \multicolumn{4}{|c|}{ Ethnic groups } \\
\hline & Tswana & \multirow{2}{*}{$\begin{array}{l}\text { Zulu } \\
95 \%\end{array}$} & $\begin{array}{l}\text { Northern } \\
\text { Sotho }\end{array}$ & Tsonga \\
\hline $\begin{array}{l}\text { Do you think as a result of } \\
\text { menopause, you are no } \\
\text { longer a real woman? }\end{array}$ & $91 \%$ & & $90 \%$ & $96 \%$ \\
\hline \multicolumn{5}{|l|}{ Answer: (No) } \\
\hline $\begin{array}{l}\text { Do you worry about losing } \\
\text { your mind because you are } \\
\text { postmenopausal? }\end{array}$ & $2 \%$ & $5 \%$ & $3 \%$ & $1 \%$ \\
\hline \multicolumn{5}{|l|}{ Answer: (Yes) } \\
\hline $\begin{array}{l}\text { Have you noticed the } \\
\text { development of wrinkles on } \\
\text { your face? }\end{array}$ & $15 \%$ & $22 \%$ & $18 \%$ & $20 \%$ \\
\hline \multicolumn{5}{|l|}{ Answer: (Yes) } \\
\hline $\begin{array}{l}\text { Have you noticed the } \\
\text { growth of beard on your } \\
\text { face since menopause? }\end{array}$ & $7 \%$ & $5 \%$ & $8 \%$ & $6 \%$ \\
\hline \multicolumn{5}{|l|}{ Answer: (Yes) } \\
\hline $\begin{array}{l}\text { Do you still regard yourself } \\
\text { as a beautiful woman } \\
\text { even though you are now } \\
\text { menopausal? }\end{array}$ & $78 \%$ & $82 \%$ & $76 \%$ & $79 \%$ \\
\hline Answer: (Yes) & & & & \\
\hline
\end{tabular}

Table 5 reflects the positive attitude of the women, in which all the four ethnic groups of menopausal women demonstrated positive attitude to the cessation of menstruation and cessation of their reproductive careers. Moreover, majority of the women in the four groups (91-98\%) were not unduly concerned about their husbands' feelings of having no further reproduction.

Table 6 shows that the cessation of menstruation is associated with a feeling of good health and the removal of the unpleasantness of menstruation. The women also reported that the cessation of menstruation had not resulted in their being sick more often than when they were still menstruating.

Table 7 shows that a disproportionate percentage of the women experienced mood changes as a result of menopause, with a greater percentage of postmenopausal

Table 6: Participant's views regarding acceptance of menopause as a natural transition in their lives

\begin{tabular}{|c|c|c|c|c|}
\hline \multirow[b]{2}{*}{ Questions } & \multicolumn{4}{|c|}{ Ethnic groups } \\
\hline & Tswana & Zulu & $\begin{array}{l}\text { Northern } \\
\text { Sotho }\end{array}$ & Tsonga \\
\hline $\begin{array}{l}\text { Are you happy that the } \\
\text { change of life has removed } \\
\text { the unpleasantness of } \\
\text { menstruation? (Yes) }\end{array}$ & $89 \%$ & $92 \%$ & $95 \%$ & $94 \%$ \\
\hline $\begin{array}{l}\text { Do you feel healthier and } \\
\text { stronger since the cessation } \\
\text { of menstruation? (Yes) }\end{array}$ & $78 \%$ & $81 \%$ & $76 \%$ & $84 \%$ \\
\hline $\begin{array}{l}\text { Do you fall sick more often } \\
\text { now, than when you were } \\
\text { still menstruating? (No) }\end{array}$ & $97 \%$ & $94 \%$ & $95 \%$ & $93 \%$ \\
\hline
\end{tabular}


Table 7: Participant's responses to possible changes in their emotional health since they attained menopause

\begin{tabular}{|c|c|c|c|c|}
\hline Question & \multicolumn{2}{|c|}{ Perimenopause } & \multicolumn{2}{|c|}{ Postmenopause } \\
\hline $\begin{array}{l}\text { Have you experienced } \\
\text { any mood changes } \\
\text { since you became } \\
\text { menopausal? (Yes) }\end{array}$ & \multicolumn{2}{|c|}{$15 \%$} & \multicolumn{2}{|c|}{$43 \%$} \\
\hline \multirow{2}{*}{$\begin{array}{l}\text { Have you been } \\
\text { experiencing difficulties in } \\
\text { sleeping at night? (Yes) }\end{array}$} & \multicolumn{2}{|l|}{$10 \%$} & \multicolumn{2}{|l|}{$48 \%$} \\
\hline & All eth & & groups & \\
\hline \multirow[t]{2}{*}{$\begin{array}{l}\text { With whom are you living } \\
\text { now? (All ethnic groups) }\end{array}$} & Alone & $\begin{array}{l}\text { With a } \\
\text { relation }\end{array}$ & $\begin{array}{l}\text { With my } \\
\text { children }\end{array}$ & $\begin{array}{l}\text { With my } \\
\text { husband }\end{array}$ \\
\hline & $35 \%$ & $18 \%$ & $25 \%$ & $22 \%$ \\
\hline $\begin{array}{l}\text { Do you feel less urge } \\
\text { to have sex with your } \\
\text { husband or partner? (Yes) }\end{array}$ & $74 \%$ & $80 \%$ & $79 \%$ & $82 \%$ \\
\hline
\end{tabular}

Table 9: Participant's knowledge of osteoporosis and HRT

\begin{tabular}{|c|c|c|c|c|}
\hline \multirow[b]{2}{*}{ Questions } & \multicolumn{4}{|c|}{ Ethnic groups } \\
\hline & Tswana & Zulu & $\begin{array}{l}\text { Northern } \\
\text { Sotho }\end{array}$ & Tsonga \\
\hline $\begin{array}{l}\text { Do you experience any pain } \\
\text { in your hip or spine? (No) }\end{array}$ & $84 \%$ & $86 \%$ & $79 \%$ & $87 \%$ \\
\hline $\begin{array}{l}\text { Have you ever had a bone } \\
\text { fracture? (No) }\end{array}$ & $97 \%$ & $98 \%$ & $99 \%$ & $96 \%$ \\
\hline $\begin{array}{l}\text { Have you ever been treated } \\
\text { for hypertension or diabetes? } \\
\text { (Yes) }\end{array}$ & $78 \%$ & $82 \%$ & $86 \%$ & $79 \%$ \\
\hline $\begin{array}{l}\text { Do you know anything about } \\
\text { HRT? (Yes) }\end{array}$ & $82 \%$ & $85 \%$ & $80 \%$ & $84 \%$ \\
\hline $\begin{array}{l}\text { Do you know that HRT } \\
\text { can reduce symptoms of } \\
\text { menopause? (Yes) }\end{array}$ & $78 \%$ & $76 \%$ & $81 \%$ & $80 \%$ \\
\hline $\begin{array}{l}\text { Have you ever sought help } \\
\text { to cope with the symptoms } \\
\text { of menopause? (No) }\end{array}$ & $81 \%$ & $84 \%$ & $77 \%$ & $86 \%$ \\
\hline $\begin{array}{l}\text { Are you afraid of using HRT? } \\
\text { (Yes) }\end{array}$ & $3 \%$ & $6 \%$ & $4 \%$ & $1 \%$ \\
\hline
\end{tabular}

women $(43 \%)$ as against perimenopausal women $(15 \%)$ reporting this phenomenon. Similarly, insomnia (sleep disturbance) seemed to be more prevalent among postmenopausal women ( $48 \%$ ) in comparison with perimenopausal women (10\%). Among all four ethnic groups a little over one third (35\%) of the women lived alone, $18 \%$ lived with their relations, $25 \%$ lived their children and 22\% lived with their husbands. The transition and changes in the women's lives as a result of perimenopause or postmenopause had very little effect on their sexual relationships with their husbands or partners.

Table 8 illustrates good coping mechanisms and good support from the husbands of these women. The majority of the women (93-97\%) had discussed their transition with their husbands and more than three-quarters of them $(\geq 78 \%)$ received direct support from their husbands/ partners in coping with the changes brought about by perimenopause or postmenopause. Regarding frequency
Table 8: The participant's relationship with her husband

\begin{tabular}{|c|c|c|c|c|}
\hline \multirow[b]{2}{*}{ Questions } & \multicolumn{4}{|c|}{ Ethnic groups } \\
\hline & Tswana & Zulu & $\begin{array}{l}\text { Northern } \\
\text { Sotho }\end{array}$ & Tsonga \\
\hline $\begin{array}{l}\text { Have you ever } \\
\text { discussed your } \\
\text { menopause with your } \\
\text { husband (Yes) }\end{array}$ & $96 \%$ & $94 \%$ & $97 \%$ & $93 \%$ \\
\hline $\begin{array}{l}\text { Is he giving you any } \\
\text { support in coping with } \\
\text { menopause? (Yes) }\end{array}$ & $80 \%$ & $84 \%$ & $78 \%$ & $91 \%$ \\
\hline $\begin{array}{l}\text { How is your sexual } \\
\text { relationship with your } \\
\text { husband/partner } \\
\text { since you attained } \\
\text { menopause? (All } \\
\text { ethnic groups) }\end{array}$ & $\begin{array}{l}\text { Frequent } \\
35 \%\end{array}$ & $\begin{array}{l}\text { Occasional } \\
25 \%\end{array}$ & $\begin{array}{l}\text { Sporadic } \\
10 \%\end{array}$ & $\begin{array}{l}\text { No } \\
\text { change } \\
30 \%\end{array}$ \\
\hline
\end{tabular}

of sexual contact with husbands/partners, 35\% had frequent sexual contact, $25 \%$ reported occasional contact, $30 \%$ reported no change, while only $10 \%$ reported that sexual contact had become sporadic since reaching perimenopause and postmenopause.

In Table 9, all the four ethnic groups showed high levels of good health as reflected by low rates of fracture as well as a low number of hip and spinal effects. The majority of the women were being treated for hypertension and diabetes. The women in the four groups were aware of the existence of HRT and the possible alleviation of psychosomatic symptoms with the therapy, yet between 77 and $86 \%$ of the women had never sought medical help to cope with the symptomatology of perimenopause and postmenopause.

\section{DISCUSSION}

The mean age at onset of menopause among women in this study, using retrospective data, was 51.6 years, which is comparable with that of other local researchers. ${ }^{11}$ It is equally comparable to the data of other developing countries in Africa, such as Nigeria ${ }^{3-5}$ and Ghana, ${ }^{12}$ and similar to the mean age of menopause of 50 years reported in Finland.$^{13}$ The accuracy of calculating the age at menopause is generally affected by differences in methodology, sample sizes, race/ethnicity as well as the accuracy of recall by the participants in the study. The accuracy of the information provided is dependent on the duration since the final episode of menstrual period, the level of motivation, and the level of education of the participants in the study. In the present study, $80 \%$ of the participants were literate, hence, the reliability of their information. The remaining $20 \%$ of the women in the study depended on milestones of important national events to recall the time of menopause.

The onset of menopause was not influenced by the level of education ${ }^{14}$ in this study. Those who were 
educated attained menopause more or less at the same time as the less educated women. However, parity may have an influence because both groups were highly parous women. Parity and gravidity are known to promote delay of menopause. ${ }^{3}$ The rationale behind this statement is that an increased number of pregnancies result in a reduced number of ovulatory cycles; hence ovarian function is preserved. In this study, the parity range was 3 to 8 . The mean age at menopause was found to be 49.5 years, a figure which is comparable with that reported in a previous study. ${ }^{11}$

The socioeconomic status of the women did not seem to have any effect on the onset of menopause. Black South African women have a positive attitude toward menopause and also demonstrate adequate knowledge about it. This is reflected by the responses given to the various questions, which proved that these women associated menopause with an elevation in their social status. They believed that they were now regarded as community counsellors and they took part in important tasks in the community, such as acting as traditional birth attendants. This positive attitude was demonstrated by $96 \%$ of the women who participated in this study. The women also explained that menopause is a state of tranquility, purity, and freedom from pregnancy and its complications. As a result of these, the women felt at liberty and play major roles in providing the needs of the initiates during circumcision ceremonies. Menstruation is associated with poor healing, while menopause is associated with promotion of wound healing. On the contrary, the women felt that their femininity was lost $(92 \%$ felt that they were no longer real women). However, $96 \%$ of the women had positive attitude toward attainment of menopause and there were no psychological disturbances and fear of losing their minds that could be attributable to menopause.

This positive attitude toward menopause is found among women of other developing countries, such as Nigeria. ${ }^{3-5,12}$ These women view menopause as a physiological state which commands tranquility, extra time of worship, and elevation of one's status. Mayan women in Mexico as well as Greek women ${ }^{15}$ show the same positive attitude toward menopause. It was a pleasant surprise to find that in her thesis, Flint ${ }^{16}$ emphasized on the importance of positive attitude to menopause. The study conducted in Israel by Maoz et $\mathrm{al}^{7}$ among different nationalities in Israel reported the same findings as those of the above studies.

Although women in developing countries are adequately cushioned by their culture so that they view menopause positively, a positive attitude toward menopause is individual. The works by Polit and Larocco ${ }^{17}$ and Bloch ${ }^{18}$ also emphasize the importance of education, which not only equips the individual with knowledge about menopause and its consequences, but equally equips women with self-awareness and confidence, thus resulting in a positive attitude toward menopause. The combined UK and Indian study ${ }^{19}$ does, in my opinion, further emphasize the importance of education for those who have been uprooted from the comfort zone of their culture.

Black South African women, as evidenced by the high rate reported in this study, are very aware of the vasomotor symptomatology and the availability of HRT as the treatment of the symptomatology. This is to be expected, as $80 \%$ of the women in this study are literate. The impact of education on the understanding of issues around menopause in this study has been previously reported by several other workers. ${ }^{17-19}$ The sources of information for most of these women are the radio and television, and the print media (83\%), mostly women's magazines. However, some measure of disappointment is felt by a high proportion of these women (81\%) who do not seek medical help for the alleviation of the symptoms. One can conclude that the role of culture probably has a major impact in the reluctance of these women to seek help.

A different opinion has been expressed by other authors. ${ }^{20,21}$ The studies in Taiwan and Singapore view education as the cause of a negative attitude toward menopause. It is supposed that the women in those studies might have come across stereotypes in the literature that influenced their negative attitude toward menopause. Women with more negative attitudes toward menopause, in general, report more symptoms during the menopausal transition. ${ }^{22}$

A study done in Mamelodi, which is the location on the eastern part of Pretoria (South Africa), has found similar results. ${ }^{23}$ The women of Mamelodi view menopause as a natural, normal process of aging. Botswana as well as Namibia are countries bordering South Africa and the cultural behavior and beliefs are similar to those found in South Africa. Hence, similar sentiments to menopause have been reported in Botswana where menopause is viewed as a period of freedom from menstruation- and labor-related problems. It is equally a cost-effective period as sanitary supplies are no more a necessity. ${ }^{24}$ In Namibia, menopause is viewed as a period of wisdom and old age, by the majority of menopausal women. ${ }^{25}$

There is a lot of similarity in attitudes between black African women and Moslem women. Work previously done by Maoz et $\mathrm{al}^{7}$ in Israel, and recent studies in Turkey and Iran, show that these women have positive attitudes toward menopause similar to what is found among black African women population. ${ }^{26,27}$

\section{CONCLUSION}

The black South African women in the present study have demonstrated adequate knowledge about menopause. Despite strong traditional and cultural beliefs about 
menopause, black South African women in this study view menopause with a positive attitude, which is in keeping with reports from studies conducted in other African countries, such as in Nigeria and Egypt. It is even more encouraging to find that even our neighboring countries, namely Botswana and Namibia women, are no different from South African women as far as their thoughts and behavior toward menopause is concerned. What is probably lacking is the ability of these women to translate their knowledge and attitude toward menopause, to seeking remedies for alleviating the vasomotor effects of menopause with HRT.

\section{REFERENCES}

1. Fritz MA, Speroff L. Menopause and the perimenopausal transition. In: Clinical gynaecologic endocrinology and infertility. 8th ed. Philadelphia: Lippincott Williams and Wilkins; 2011. pp. 673-748.

2. Sassarini J, Fox H, Ferrell W, Satter N, Lumsden MA. Hot flushes, Vascular reactivity and the role of the $\alpha$-adrenergic system. Climacteric 2012 Aug;15(4):332-338.

3. Olaolorun F, Lawoyin T. Age at menopause and factors associated with attainment of menopause in an urban community in Ibadan, Nigeria. Climacteric 2009 Aug;12(4):352-363.

4. Adekunle AO, Fawole AO, Okonlola MA. Perceptions and attitudes of Nigerian women about the menopause. J Obstet Gynaecol 2000 Sep;20(5):525-529.

5. Osinowo HO. Psychosocial factors associated with perceived psychological health, perception of menopause and sexual satisfaction in menopausal women and controls. West Afr J Med 2003 Sep;22(3):225-231.

6. Ande AB, Omu OP, Ande OO, Olagbuji NB. Features and perceptions of menopausal women in Benin City, Nigeria. Ann Afr Med 2011 Oct-Dec;10(4):300-304.

7. Maoz B, Antonovsky A, Apter A, Wijsewbeek H, Datan N. The perceptions of menopause in the five ethnic groups in Israel. Acta Obstet Gynecol Scand Suppl 1977;65:69-76.

8. Manson JM, Sammel MD, Freeman EW, Grisson JA. Racial differences in sex hormone levels in women approaching the transition to menopause. Fertil Steril 2001 Feb;75(2):297-304.

9. Freeman EN, Sammel MD, Gracia CR, Kapoor S, Lin H, Liu L, Nelson DB. Follicular phase hormone levels and menstrual bleeding status in the approach to menopause. Fertil Steril 2005 Feb;83(2):383-392.

10. Malik HS. Knowledge and attitude towards Menopause and Hormone replacement therapy (HRT) among postmenopausal women. J Pak Med Assoc 2008 Apr;58(4):164-167.

11. Walker AR, Walker BF, Ncongwane J, Tshabalala EN. Age of menopause in black women in South Africa. Br J Obstet Gynaecol 1984 Aug;91(8):797-801.
12. Kwawukume EY, Ghosh TS, Wilson JB. Menopausal age of Ghana women. Int J Gynaecol Obstet 1993 Feb;40(2): 151-155.

13. Huoto R, Kaprio J, Uutela A. Age at natural menopause and socio-demographic status in Finland. Am J Epidemiol 1994;139:64-76.

14. Otolorin EO, Adeyefa I, Osotimehin BO, Fatinikun T, Ojengbede $\mathrm{O}$, Otubu JO, Ladipo OA. Clinical hormonal and biochemical features of menopausal women in Ibadan, Nigeria. Afr J Med Med Sci 1989 Dec;18(4):251-255.

15. Beyene Y. Cultural significance and physiological manifestation of menopause: a bio-cultural analysis. Cult Med Psychiatry 1986 Mar;10(1):47-71.

16. Flint M. The menopause: reward or punishment. Psychosomatics 1975;16:161-163.

17. Polit DF, Larocco SA. Social and psychological correlates of menopausal symptoms. Psychosom Med 1980 May;42(3): 335-345.

18. Bloch A. Self-awareness during menopause. Maturita 2002 Jan 30;41(1):61-68.

19. Hunter MS, Guptar P, Papitsch-Clark A, Sturdee DW. Mid-age health in women from the Indian sub-continent: A further quantitative/qualitative investigation of experience of menopause in UK Asian women, compared with UK Caucasian women and women living in New Delhi. Climacteric 2009 Feb;12(1):26-37.

20. Harvey C, Ian BH, Aug CC, Chew EM, Chong YS, Saw SM. The prevalence of menopausal symptoms in a community in Singapore. Maturitas 2002 Apr 25;41(4):275-282.

21. Groeneveld FP, Bareman FP, Barentsen R, Dokter HJ, Drogendijk AC, Hoes AW. Relationships between attitudes towards menopause, well-being and medical attention among women aged 45-60 years. Maturitas 1993 Sep;17(2):77-88.

22. Ayers A, Forshaw M, Hunter MS. The impact of attitudes towards the menopause on women's symptom experience: a systematic review. Maturitas 2010 Jan;65(1):28-36.

23. Rikhotso SR, Makuwa GN, Mulaudzi FM. The perception of African women regarding natural menopause in Mamelodi, Tshwane district. Corationus 2015 Dec 17;38(2):1531.

24. Njoku OA, Ngome E. Menopausal perceptions and experiences of older women from selected sites in Botswana. Adv Sex Med 2013;3:47-59.

25. Hoebes $\mathrm{KH}$, Matengu K. Knowledge and understanding of menopause and menopausal symptoms: a Namibian perspective. Int J Health Sci 2014;2:163-183.

26. Noroozi E, Dolatabadi NK, Eslami AA, Hassanzadeh A, Davari S. Knowledge and attitude toward menopause phenomenon among women aged 40-45 years. J Educ Health Promot 2013 May 30;2:25.

27. Yanikkerem E, Koltan SO, Tamay AG, Dikayak Ş. Relationship between women's attitude towards menopause and quality of life. Climacteric 2012 Dec;15(6):552-562. 